\title{
Inhibitory and Excitatory Responses to Field Stimulation in Fetal and Adult Pig Airway
}

\author{
H. W. MITCHELL, M. P. SPARROW, AND R. P. TAGLIAFERRI
}

Department of Physiology, University of Westem Australia, Nedlands, 6009. Australia

\begin{abstract}
The innervation in airway tissues from young adult (15-26 wk) and fetal (95/115 d gestation) pigs was compared in isolated tracheal and bronchial preparations subjected to electrical field stimulation. End-organ responsiveness to carbachol, substance P, isoprenaline, and VIP was present by 95 d gestation. Electrical field stimulation $(0.5-20 \mathrm{~Hz}, 70 \mathrm{~V}, 0.5 \mathrm{~ms})$ resulted in a frequency-dependent contraction that was blocked by atropine $\left(10^{-6} \mathrm{M}\right)$ and TTX $\left(10^{-6} \mathrm{M}\right)$ at both ages. However, there was a 10 -fold increase in threshold in the fetal airways because contractions were evoked at frequencies of approximately $5 \mathrm{~Hz}$ in the fetus compared with $0.5 \mathrm{~Hz}$ in the young adult airways. In the young adult airways, there were atropine-resistant contractions at longer pulse durations ( $1-5 \mathrm{~ms}, 20 \mathrm{~Hz}$ ), but not usually in the fetus. The atropine-resistant contractions were not blocked by TTX. Capsaicin $\left(10^{-6} \mathrm{M}\right)$ produced no contraction in the pig airway. In tissues contracted using the $\mathbf{E D}_{\mathbf{5 0}}$ of carbachol, electrical stimulation $(1-20 \mathrm{~Hz}, 70$ $\mathrm{V}, 1 \mathrm{~ms})$ caused marked relaxation, however, compared with those in the young adult, fetal responses were weak or absent. Propranolol $\left(10^{-6} \mathrm{M}\right)$ partially reduced the relaxation of the yonng adult bronchus $(\sim 25 \%)$, but it had little effect on responses in the other young adult and fetal preparations. Therefore, the inhibitory innervation of pig airways was predominantly nonadrenergic and the excitatory component was cholinergic. Neither of these components was fully developed in the fetus close to term. ( $P e$ diatr Res 28: 69-74, 1990)
\end{abstract}

\section{Abbreviations}

VIP, vasoactive intestinal polypeptide TTX, tetrodotoxin

Adult airways smooth muscle is innervated by cholinergic excitatory pathways (1) and an inhibitory pathway that is predominantly nonadrenergic in man (2), but that is both adrenergic and nonadrenergic in guinea-pigs (3). Additionally, an atropineresistant contraction to electrical field stimulation in vitro indicates that there is a noncholinergic excitatory mechanism, at least in the guinea-pig (4), but evidence in man for such a mechanism is indirect and relies on the presence of a contraction evoked by the neurotoxin capsaicin (5). The innervation may not only initiate bronchoconstriction or bronchodilation in vivo, but may also modulate motor responses to mediators such as histamine and, therefore, may be important in determining airway caliber and nonspecific bronchial responsiveness.

Recent interest has focused on the responsiveness of airways

Received June 8, 1989; accepted March 16, 1990.

Correspondence: Dr. H. W. Mitchell, Department of Physiojogy, University of Western Australia, Nedlands, Australia, 6009.

Supported by the Australian Research Council. in infancy and childhood. There appears to be little information on the postnatal development of the excitatory and inhibitory innervation of airways smooth muscle and no information on its function before birth. Resting vagal tone could not be demonstrated in newborn pigs in vivo (6), whereas electrical stimulation of the efferent vagus causes tracheal pressure to rise in 1d-old rabbits, but, compared with the adult, responses were poorly sustained (7). Vagal myelinated fibers are fewer in the newborn cat than in the adult $(8,9)$. It is, therefore, possible that the functional innervation of airway in the newborn is immature. This may be evidenced as a shift in the balance between constrictor and dilator pathways and could thus be important in bronchial responsiveness.

In these experiments, we subjected isolated airways smooth muscle from pigs to electrical field stimulation and recorded subsequent contractile or relaxant responses. Responses in tissues from young adult pigs were compared with those in the late term fetus to determine the types of neurotransmission present just before birth.

\section{MATERIALS AND METHODS}

Airways (and fetuses) were obtained from pigs within $20 \mathrm{~min}$ of slaughter. The lungs were immediately placed in chilled Krebs solution upon collection and transported to the laboratory before use (usually $\sim 1 \mathrm{~h}$ ). Two age groups were studied: young adult animals (40-65 kg body wt, 15-26 wk) and fetuses (95 d gestation, $\sim 0.8 \mathrm{~kg}$ body wt). Gestation is approximately $115 \mathrm{~d}$ in this species.

Nineteen pigs of either sex were used in our study-nine fetal and 10 young adult. The fetal pigs were from four litters. Transverse strips of trachealis and secondary bronchi, approximately $3 \mathrm{~mm} \times 5 \mathrm{~mm}$ in the fetus and $3 \mathrm{~mm} \times 10 \mathrm{~mm}$ in the young, were prepared from each pig. From the young animals, a total of 12 tracheal and 12 bronchial preparations were studied, whereas from the fetal pigs, a total of 16 bronchi and 16 tracheas were used (i.e. 2-4 airway preparations/pig at both ages). The tissues were clamped in an organ bath $\left(37^{\circ} \mathrm{C}\right)$ containing a Krebs solution ( $\mathrm{pH} 7.4$, gassed with $95 \% \mathrm{O}_{2}$ and $5 \% \mathrm{CO}_{2}$ ) and electrically stimulated by platinum plate electrodes placed some $4 \mathrm{~mm}$ on either side of the tissue. One end of the tissue was secured to a force transducer (FT03, Grass Instruments Co., Quincy, MA) connected to a flat bed chart recorder for measuring contractile and relaxant responses. Optimal passive force $(0.5 \mathrm{~g}$ in the fetus and $1 \mathrm{~g}$ in the young adult) was applied by gently stretching. These passive forces were previously established by us from the length-force properties of pig tissues of different ages. For this purpose, active force was developed in response to alternating field current ( $100 \mathrm{~V}, 50 \mathrm{~Hz}$ for $4 \mathrm{~s}$ ). Tissues were challenged with several submaximal concentrations of carbachol before and during the experimental protocols (see below) to ensure reproducibility of muscie contraction.

Full concentration-response curves to carbachol were obtained in some preparations (one trachea and one bronchus from each of four pigs/age). From these, the $\mathrm{ED}_{50}$ and maximum tissue 
response were determined. In most experiments, excitatory and inhibitory responses to field stimulation were examined in different tracheal or bronchial preparations. Contractile responses were obtained in tissues from four young adult and seven fetal pigs by delivering $1 \mathrm{~min}$ trains of impulses at varying frequencies $[0.5-20 \mathrm{~Hz}, 0.5 \mathrm{~ms}$ duration at maximum voltage $(70 \mathrm{~V})]$. These responses were cholinergic (see Results). A 4- to 5-min interval was allowed between successive stimulations. Frequency-response curves were constructed in duplicate and the results from each tissue were averaged. A third frequency-response curve was obtained after the addition of $10^{-6} \mathrm{M}$ atropine to the bath. This concentration of atropine abolished maximal contractions to carbachol. Subsequently, the preparations were stimulated at 20 $\mathrm{Hz}$, but with an increased pulse width (1-5 or $10 \mathrm{~ms})$ to investigate possible noncholinergic excitation (4). Responses to field stimulation were normalized against the maximum contraction to carbachol in each preparation.

In a further six young adult and seven fetal pigs, inhibitory responses ( $1 \mathrm{~ms}$ pulses, $70 \mathrm{~V}, 0.5-20 \mathrm{~Hz}$ ) were determined after raising tone with carbachol. Care was taken to ensure that the concentration of carbachol used produced half the maximal contraction (i.e. the $\mathrm{ED}_{50}$ ) as previously determined. The $\mathrm{ED}_{50}$ concentration was different in the trachea compared with the bronchi, but it was the same in the two age groups (see Results). Field stimulation for $1 \mathrm{~min}$, was sufficient to elicit maximum relaxation. In tissues from four fetal and four young pigs, relaxation-responses were determined before and after propranolol $\left(10^{-6} \mathrm{M}\right)$. Carbachol was used to raise tone because pig airways do not develop sustained contraction to histamine and responses to 5-hydroxytryptamine and leukotrienes are weak or varied. High potassium or calcium ionophore was considered inappropriate because of possible effects on nerve endings. Indeed, in two young adult and three fetal bronchi, we found that neurogenic relaxation-responses could not be elicited in the presence of high external potassium $\left[\left(\mathrm{K}^{+}\right)_{i}=50 \mathrm{mM}\right]$.

The following drugs were used: carbamylcholine chloride, atropine sulphate, propranolol hydrochlonide, isoprenaline hydrochloride, capsaicin, substance P, TTX, and VIP. All the drugs were obtained from Sigma Chemical Co., Inc. (St. Louis, MO) except for substance P (Auspep, Melbourne, Australia).

Stock solutions of the drugs were made up in double-distilled water and stored at $4^{\circ} \mathrm{C}$. Diluted solutions were made up in Krebs solution each day as required and were kept on ice during the experiment. Capsaicin was initially dissolved in a few drops of ethanol and then made to volume in $0.9 \%$ saline solution.

\section{RESULTS}

Airway preparations from both ages contracted when exposed to carbachol. Because of their smaller size, the force developed by fetal tissues was usually less than that in the young adult. Therefore, contractions were corrected for wet wt. In the trachea, maximum force was $0.42 \pm 0.02 \mathrm{~g} / \mathrm{mg}$ (mean \pm SEM) in the young adult and $0.43 \pm 0.05 \mathrm{~g} / \mathrm{mg}$ in the fetus. In the bronchus, maximum contractions were $0.028 \pm 0.008 \mathrm{~g} / \mathrm{mg}$ in the young adult and $0.09 \pm 0.01 \mathrm{~g} / \mathrm{mg}$ in the fetus. The sensitivities $\left(\mathrm{ED}_{50}\right)$ to carbachol were not different in the two ages but the tracheas were more sensitive than the bronchi. The $\mathrm{ED}_{50}$ was $6.9 \pm 3.0 \times$ $10^{-7} \mathrm{M}$ and $7.8 \pm 1.3 \times 10^{-7} \mathrm{M}$ in the young adult and fetal tracheas, respectively, and $9.1 \pm 1.1 \times 10^{-7} \mathrm{M}$ and $1.5 \pm 0.1 \times$ $10^{-6} \mathrm{M}$ in the bronchus $(n=4$ animals/age for each of the above).

Field stimulation $(0.5 \mathrm{~ms}, 70 \mathrm{~V})$ of bronchi and tracheas from four young adult and seven fetal pigs resulted in a prompt contractile response that was reversed at the end of the stimulation (Fig. 1). Responses in the trachea and bronchi appeared to be identical. Relaxation of the resting airway was not seen because of the absence of intrinsic tone in these preparations. Responses were frequency dependent, but the threshold frequency for eliciting a response was significantly different in the
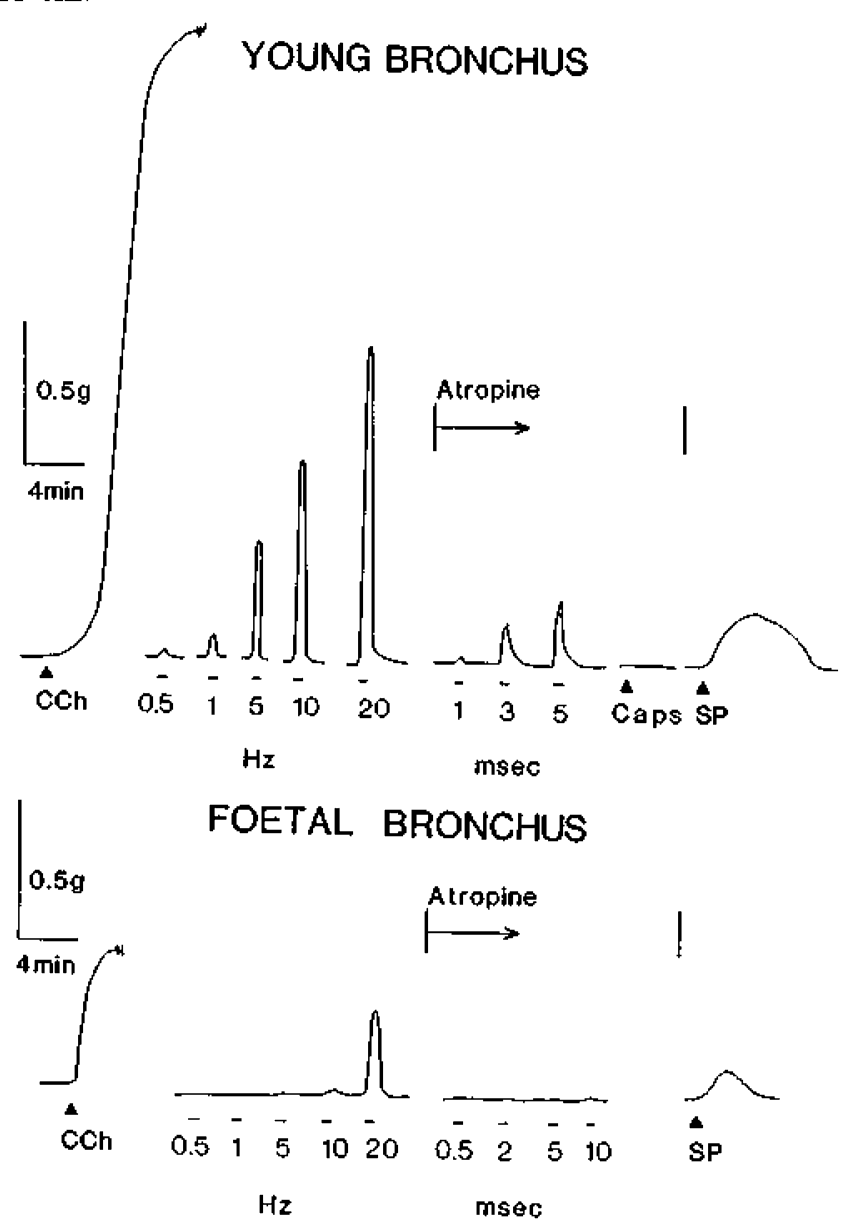

Fig. 1. Airway responses to carbachol $\left(\mathrm{CCh}, 10^{-5} \mathrm{M}\right)$, electrical field stimulation $(70 \mathrm{~V})$, capsaicin (Caps, $\left.10^{-6} \mathrm{M}\right)$, and substance $\mathrm{P}\left(S P, 10^{-6}\right.$ M). Note that less force was developed in fetal tissues to carbachol. This was associated with the small sizes of these tissues. Tissues were subjected to trains of pulses at varying frequencies $(0.5-20 \mathrm{~Hz}, 0.5 \mathrm{~ms})$, then, after addition of atropine $\left(10^{-6} \mathrm{M}\right)$ to organ baths, to varying pulse durations (1-10 ms, $20 \mathrm{~Hz}$ ). The bronchi from young pigs were more sensitive to low frequencies of stimulation and they displayed an atropine-resistant contraction with pulses of longer duration.

two ages. In young adult tissues, six of eight preparations (four tracheas and four bronchi) responded at $0.5 \mathrm{~Hz}$ and all eight preparations did so at $1 \mathrm{~Hz}$. However, of the seven fetal pigs, preparations from only two responded at 0.5 or $1 \mathrm{~Hz}$ stimulation. At $5 \mathrm{~Hz}$, approximately half of the preparations contracted. All fetal tissues responded by $10 \mathrm{~Hz}$. The frequency-response characteristics are shown in Figure 2. Contractions to field stimulation at this pulse width were abolished by atropine $\left(10^{-6} \mathrm{M}\right)$ or $\operatorname{TTX}\left(10^{-6} \mathrm{M}\right)$.

Stimulation with increased pulse duration (to $5 \mathrm{~ms}$ ) in atropinized tissues from young animals resulted in residual contractions (Figs. 1 and 3). Responses in tracheal and bronchial preparations were not different and the data were combined in Figure 3 . The magnitude of these noncholinergic responses was, however, slight, averaging some $8 \%$ of the carbachol maximum compared with cholinergic neural responses that were approximately $65 \%$ of the carbachol maximum (Fig. 2). The atropine-resistant contractions were resistant to TTX $\left(10^{-6} \mathrm{M}\right)$. Similar contractions (at $5 \mathrm{~ms}$ ) could also be elicited in preparations pretreated with TTX but not with atropine. Atropine-resistant contractions in young tissues were not different whether obtained early $(\sim 1 \mathrm{~h})$ or later $(\sim 5 \mathrm{~h})$ in an experiment after the airway had been subjected to frequent electrical stimulation.

In tissues from fetal pigs, atropine-resistant contractions were not seen in 10 of 14 tissues studied, even at $10 \mathrm{~ms}$ (Fig. 1). The remaining preparations exhibited some atropine-resistant con- 